\title{
Pelvic Peritonitis Caused by Campylobacter rectus Infection: Case Report and Literature Review
}

\author{
Anaelle Veyrine ${ }^{\mathrm{a}}$, Julie Sturque ${ }^{\mathrm{a}}$, Aude-Sophie Zlowodski ${ }^{\mathrm{a}}$, Tom Sourimant ${ }^{\mathrm{a}}$, \\ Maina Le Gal ${ }^{\mathrm{a}}$, Frederic Denis ${ }^{\mathrm{a}, \mathrm{b}, \mathrm{c}}$
}

\begin{abstract}
Campylobacter rectus (CR) is an exclusively oral, Gram-negative anaerobe and mobile bacterium that shows a wide range of virulence factors. A 41-year-old woman came to the emergency department because she felt intense radiating pain in the whole abdomen. A molecular biology analysis rapidly revealed a tubo-ovarian abscess caused by CR. A focal infection of periodontal origin was the most probable; nevertheless the possibility of a cross-contamination from her husband suffering from an active periodontal disease was the subject of discussions. The incidence of focal infections due to $\mathrm{CR}$ is probably underestimated. The introduction of molecular biology in common practice should reveal a larger number of $\mathrm{CR}$ focal infection cases but more generally speaking of bacteria from the oral cavity.
\end{abstract}

Keywords: Infection; Extra-oral; Campylobacter rectus; Wolinella recta; Mass spectrometry

\section{Introduction}

Campylobacter rectus (CR) is an exclusively oral, Gramnegative anaerobe and mobile bacterium that shows a wide range of virulence factors, in particular the flagellum, the proteins in the superficial layer, the repeats-in-toxin (RTX) toxins, the GroEL-like proteins and the lipopolysaccharide [1]. CR is involved as direct or indirect pathogen in periodontal diseases. CR can also be found in the necrotic radicular root canals [2]. CR was isolated in cases of appendicitis for patients who suffered from Barett's esophagus and extra-oral abscesses [3].

We would report the case of a pelvic peritonitis caused by CR whose origin shall be discussed a posteriori.

Manuscript submitted February 27, 2019, accepted March 11, 2019

aOdontology Department, University Hospital, Tours, France

bEA 75-05 Education, Ethique, Sante, Universite Francois-Rabelais Tours, Faculte de Medecine, Tours, France

${ }^{\mathrm{c} C o r r e s p o n d i n g ~ A u t h o r: ~ F r e d e r i c ~ D e n i s, ~ O d o n t o l o g y ~ D e p a r t m e n t, ~ U n i v e r s i t y ~}$ Hospital, Chambray les Tours 37170, France. Email: frederic.denis@chutours.fr

doi: https://doi.org/10.14740/jmc3275

\section{Case Report}

A 41-year-old woman of Caucasian origin came to the emergency department because she had been feeling intense pelvic pain for 10 days that radiated into the whole abdomen accompanied by diarrhea. The medical history is ligation-transection of the Fallopian tubes received 3 months earlier and asthma treated with salbutamol by inhalation.

The clinical examination reveals a fever of $39.5^{\circ} \mathrm{C}$. The abdomen is tense, taut and painful on palpation. The uterus palpation is painful too. The biological analyses confirm the sepsis: leucocytosis $(31.4 \mathrm{~g} / \mathrm{L})$ with predominant polynuclear neutrophils $(85.5 \%)$, monocytes $(2.36 \mathrm{~g} / \mathrm{L})$ and an increased C-reactive protein $(414 \mathrm{mg} / \mathrm{L})$.

The pelvic ultrasound shows a complex adnexal mass on the left ovary. A control computed tomography (CT) scan reveals a left tubo-ovarian abscess together with pelvic peritonitis (Fig. 1).

Following her admission to the emergency department the patient underwent surgery with drainage of the tubo-ovarian abscess together with a left partial salpingectomy and then she received a medical treatment with empiric broad-spectrum antibiotics (association of rocephin, metrodinazole, doxycycline and gentamicin) administrated intravenously during $48 \mathrm{~h}$. The mass spectrometry of matrix-assisted laser desorption/ionization time-of-flight (MALDI-TOF) identified a CR infection and the patient was administrated a targeted antibiotic treatment of intramuscular rocephin $(1 \mathrm{~g})$ during 15 days associated with metronidazole per os $(1,500 \mathrm{mg})$ during 21 days.

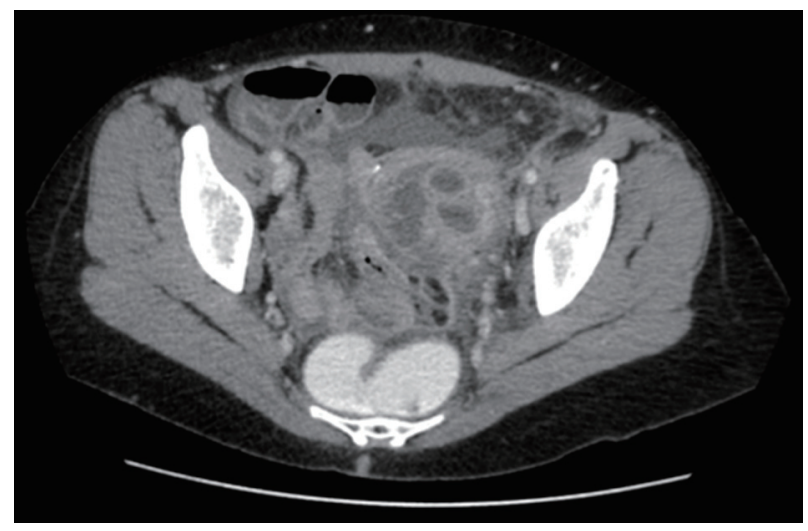

Figure 1. Abdominal CT scan showing a left tubo-ovarian abscess. 


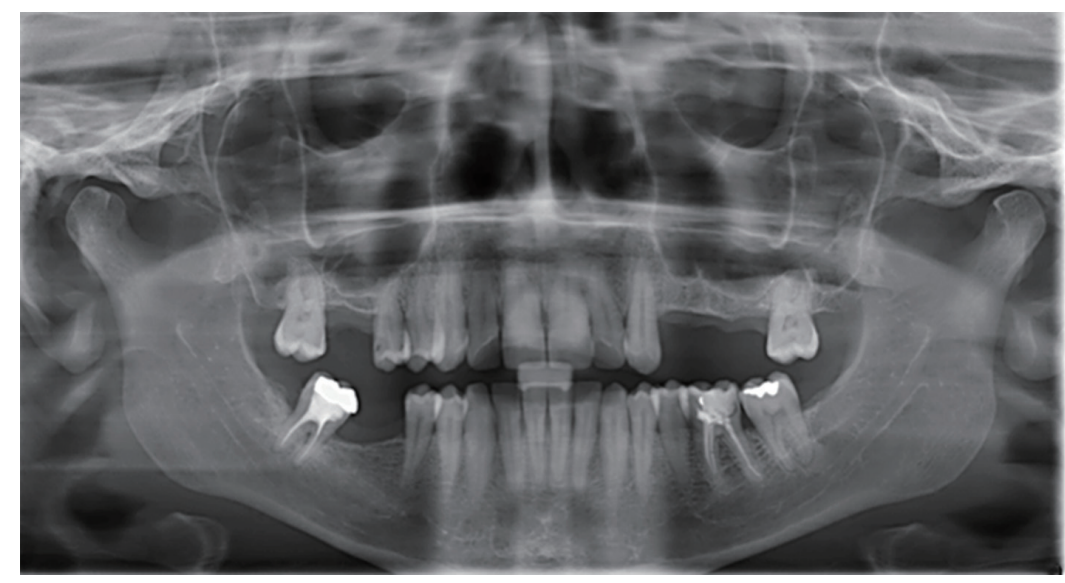

Figure 2. Dental panoramic radiography.

Following recovery the patient was sent for an odontological assessment in order to check her bucco-dental health and to identify a posteriori the portal of entry of the pathogen. The clinical examination showed a good bucco-dental condition in spite of a generalized stabilized light periodontal chronic disease. The periodontal probing revealed 3 to $4 \mathrm{~mm}$ deep pockets with no associated gingival inflammation or bleeding. The radiological examination (Fig. 2) revealed a thickening of the ligaments on two teeth with no symptomatology of an inflammatory peri-radicular lesion of endodontic origin, characterized by apical pain or radiolucent abscess. A periodontal maintenance was undertaken to control this periodontal disease.

\section{Discussion}

As a whole, 15 cases of extra-oral infections with $\mathrm{CR}$ were reported in published clinical data, affecting different tissues (Table 1) [4-16]. The patient's recovery mainly depends upon his general health condition, the site affected by the infection but also a quick identification of $\mathrm{CR}$ and the provision of a proper and efficient treatment.

The identified risk factors associated with an extra-oral infection with $\mathrm{CR}$ are a lack of oral hygiene, a periodontal disease or a dental abscess [4-10]. They can be aggravated by immunosuppression induced by health reasons that could potentiate conditions such as diabetes, chronic alcoholism, a cancerous pathology, a kidney failure or neutropenia [4, 6, 8, 10-12]. Finally, an invasive procedure performed close to a site infected with CR contributes to hematogenous spread. Cases of maxillary and cerebral infections were reported following dental avulsions [9, 13], the case of a breast abscess following nipple piercing [11], and a ligation-transection of the Fallopian tubes followed by a tubo-ovarian abscess in the case we are dealing with. Three cases do not have identified risk factors [14-16].

In this case a focal infection of periodontal origin is the most probable even if we cannot formally prove it. Indeed, the targeted antibiotic treatment significantly reduced the bacterial load of this pathogen and had the bacterial analysis of the periodontal pockets of the host at a distance from the infection unnecessary.

In this context, we wanted to check the possibility of a cross-contamination from the patient's husband. Indeed, the latter's clinical examination revealed an active periodontal disease with pockets as deep as $5 \mathrm{~mm}$ at some sites and with bleeding during associated probing. The bacteria collections into the periodontal pockets were analyzed by mass spectrometry of MALDI-TOF; however the presence of CR was not found.

Even if the hypothesis of a contamination of periodontal origin is the most probable, the concept of a focal infection remains disputable since it is difficult to absolutely prove that an extra-buccal infection has been caused by bacteria from the oral cavity. Animal experimentation and clinical studies put forward several physiopathological mechanisms: bacteremia, intervention of toxins, immunologic mechanisms and/or swallowing of dental plaque $[4,17]$. However, it remains difficult to isolate at the same time the same bacteria in the oral cavity and in the infected site with a positive biological analysis.

\section{Conclusions}

The incidence of focal infections with CR is probably underestimated because investigations are only conducted occasionally, due to the culture conditions and the cost. The introduction of molecular biology in common practice should reveal a larger number of CR focal infection cases but more generally speaking of bacteria in the oral cavity.

\section{Acknowledgments}

The authors thank Micheneau Christelle for his help with English language correction.

\section{Financial Disclosure}

None to declare. 

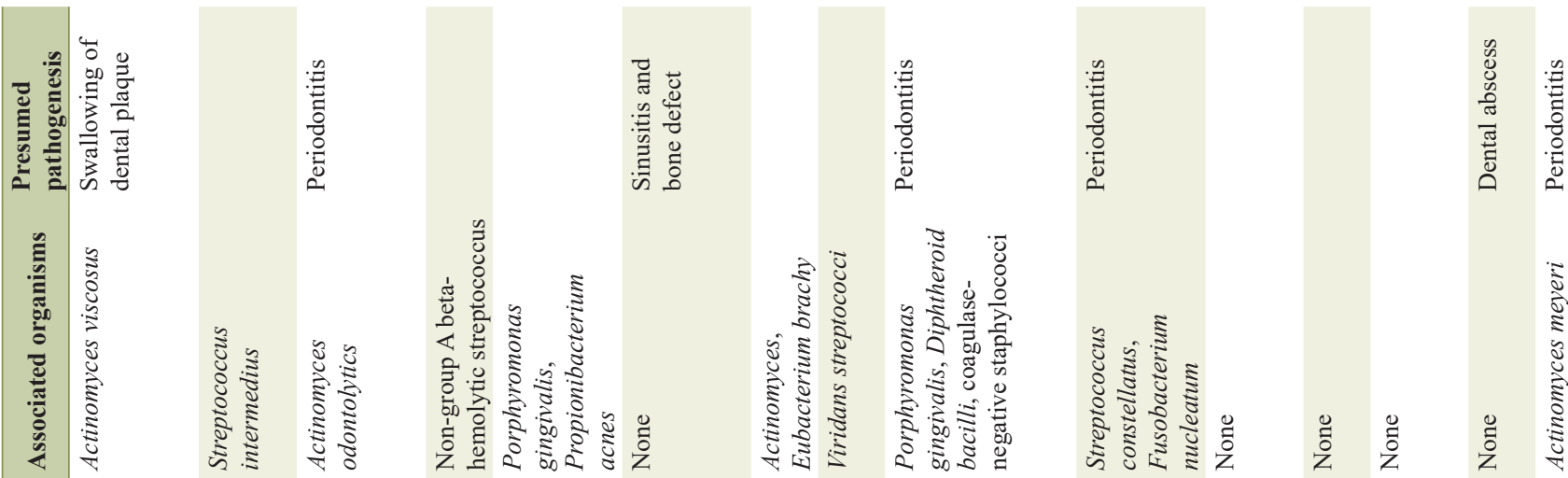

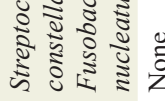

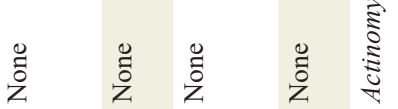

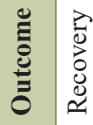

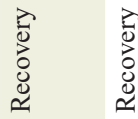

总

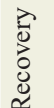

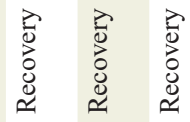

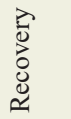

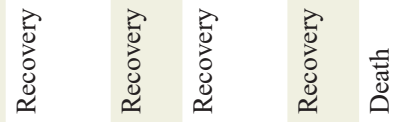

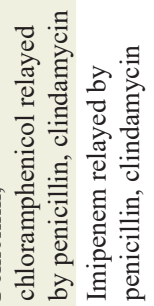

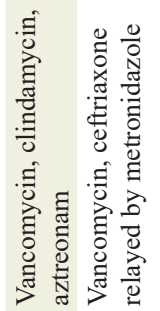
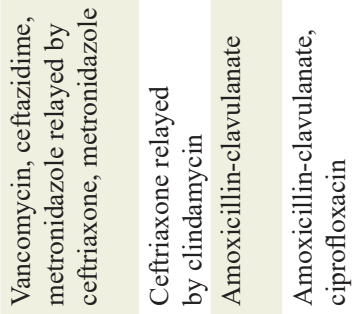

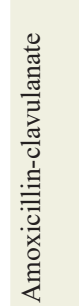

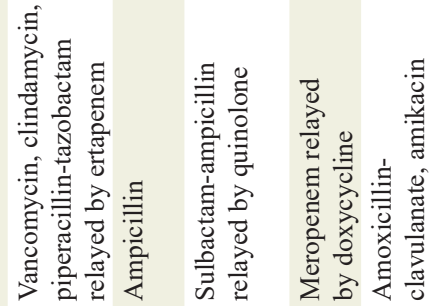

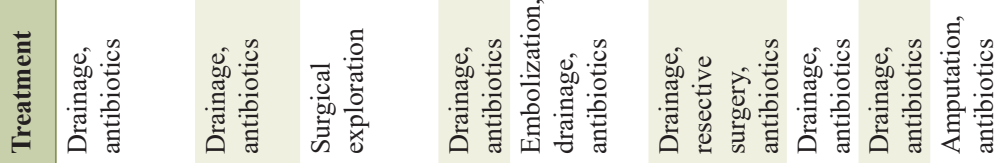

ఖ

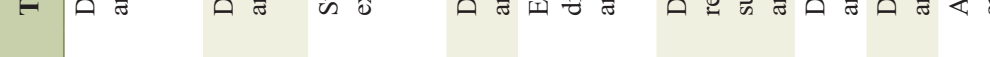

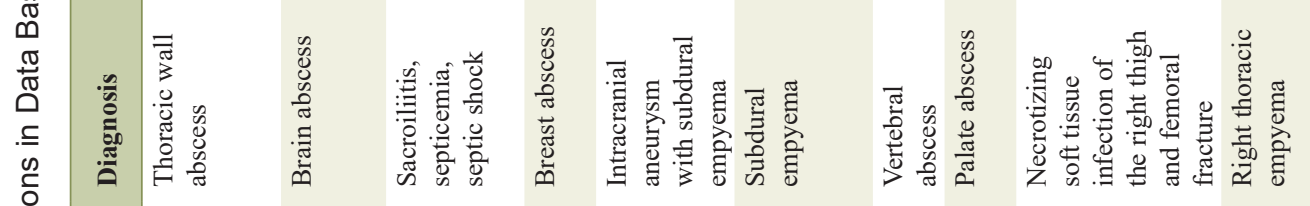

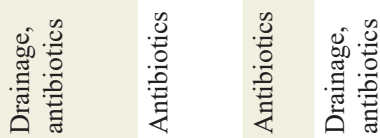

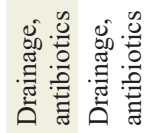

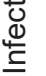

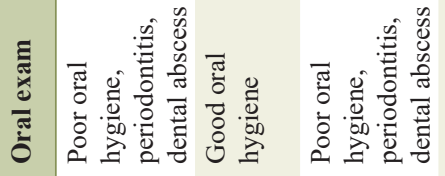

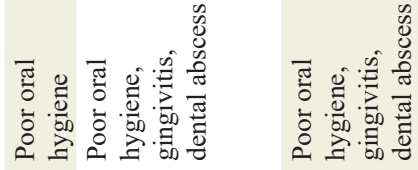

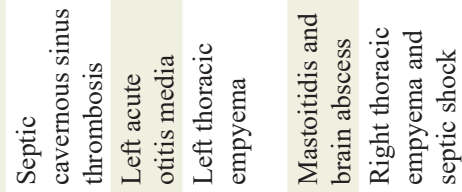

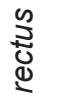
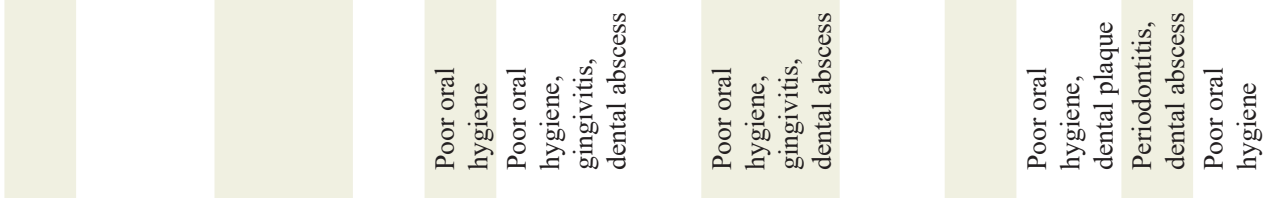

ब

$\frac{\text { है }}{\frac{0}{2}}$

ญั

蓄

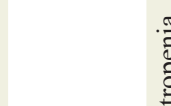

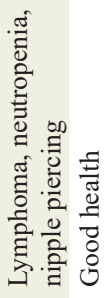
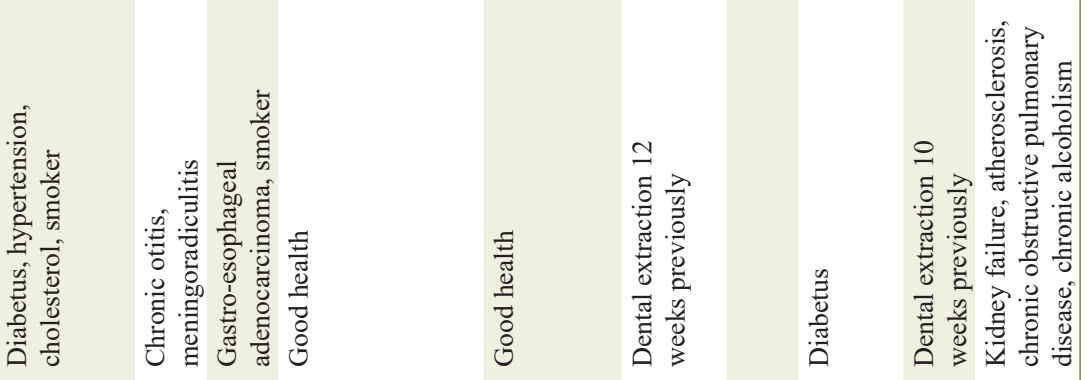

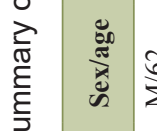

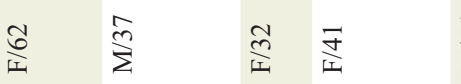

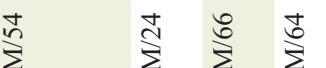

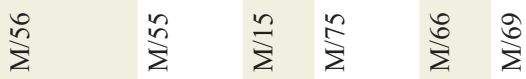

$\stackrel{5}{\circ}$

๕ิ ฐั

๕ั่

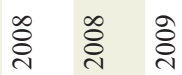

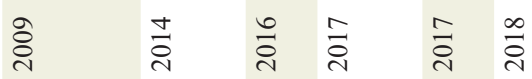

㐫

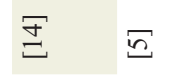

$\Xi \Xi$

$\Xi \quad \Xi \Xi$

$\Xi \quad \bar{\Xi} \Phi \Phi \Xi$ 


\section{Conflict of Interest}

None to declare.

\section{Informed Consent}

Patient agreed with publication of this case report.

\section{Author Contributions}

All the authors revised the manuscript, and approved the final content of the manuscript.

\section{References}

1. LaGier MJ, Threadgill DS. Identification of novel genes in the oral pathogen Campylobacter rectus. Oral Microbiol Immunol. 2008;23(5):406-412.

2. Ihara H, Miura T, Kato T, Ishihara K, Nakagawa T, Yamada S, Okuda K. Detection of Campylobacter rectus in periodontitis sites by monoclonal antibodies. J Periodontal Res. 2003;38(1):64-72.

3. Debruyne L, Gevers D, Vandamme P. Taxonomy of the family Campylobacteraceae. Campylobacter. 2008;3-25.

4. Spiegel CA, Telford G. Isolation of Wolinella recta and Actinomyces viscosus from an actinomycotic chest wall mass. J Clin Microbiol. 1984;20(6):1187-1189.

5. Harvey P, Bayardelle P, Belanger R, Fortin L. Sacroiliitis and septicemia caused by Campylobacter rectus and Actinomyces odontolyticus. Can J Infect Dis. 1994;5(3):133-136.

6. Mahlen SD, Clarridge JE, 3rd. Oral abscess caused by Campylobacter rectus: case report and literature review. J Clin Microbiol. 2009;47(3):848-851.
7. Lam JY, Wu AK, Ngai DC, Teng JL, Wong ES, Lau SK, Lee RA, et al. Three cases of severe invasive infections caused by Campylobacter rectus and first report of fatal C. rectus infection. J Clin Microbiol. 2011;49(4):1687-1691.

8. Ogata T, Urata T, Nemoto D, Hitomi S. Thoracic empyema caused by Campylobacter rectus. J Infect Chemother. 2017;23(3):185-188.

9. Martiny D, Dauby N, Konopnicki D, Kampouridis S, Jissendi Tchofo P, Horoi M, Vlaes L, et al. MALDI-TOF MS contribution to the diagnosis of Campylobacter rectus multiple skull base and brain abscesses. New Microbes New Infect. 2017;19:83-86.

10. Noel A, Verroken A, Belkhir L, Rodriguez-Villalobos H. Fatal thoracic empyema involving Campylobacter rectus: A case report. Anaerobe. 2018;49:95-98.

11. Han XY, Tarrand JJ, Rice DC. Oral Campylobacter species involved in extraoral abscess: a report of three cases. J Clin Microbiol. 2005;43(5):2513-2515.

12. Walter HL, Perloff S, Jungkind D, Measley R. A campylobacter rectus subdural empyema. Infect Dis Clin Pract. 2008; 16:332-334.

13. Leo QJ, Bolger DT, Jr. Septic cavernous sinus thrombosis due to Campylobacter rectus infection. BMJ Case Rep. 2014;2014.

14. Marrie TJ, Kerr E. Brain abscess due to Wolinella recta and Streptococcus intermedius. Can J Infect Dis. 1990;1(1):31-34.

15. de Vries JJ, Arents NL, Manson WL. Campylobacter species isolated from extra-oro-intestinal abscesses: a report of four cases and literature review. Eur J Clin Microbiol Infect Dis. 2008;27(11):1119-1123.

16. Kakuta R, Hidaka H, Yano H, Okamoto M, Ozawa D, Endo S, Kaku M, et al. First report of severe acute otitis media caused by Campylobacter rectus and review of the literature. J Infect Chemother. 2016;22(12):800-803.

17. Gendron R, Grenier D, Maheu-Robert L. The oral cavity as a reservoir of bacterial pathogens for focal infections. Microbes Infect. 2000;2(8):897-906. 